\title{
Profile of Fever of Unknown Origin in Children and the Role of Investigation: An Observational Study
}

\author{
P. Aparna Reddy, M. Shravani Reddy \\ Rainbow Children's Hospital, Hyderabad, India
}

\begin{abstract}
Objectives: Fever of Unknown Origin (FUO) in children remains difficult to diagnose. This prospective, observational study aimed to determine the clinico-etiological profile and the role of clinical procedures in establishing the diagnosis.
\end{abstract}

Methods: Children (between 1 month and 16 years) with prolonged fever meeting the criteria of FUO were included. A detailed medical history, physical examination and laboratory tests were conducted according to an algorithm (phase I-III). Clinical procedures that were useful in obtaining final etiology were evaluated.

Results: In total, 69 children were enrolled, categorized into five groups based on etiology of FUO. Infections (31.8\%) were the leading cause followed by malignancy $(20.2 \%)$, connective tissue disorder and miscellaneous conditions (14.5\%); undiagnosed patients (18.8\%) had either a spontaneous resolution or incomplete workup. Duration of fever was 20-60 days, longer in malignancies, least in infections and mean \pm SD duration between admission and a definitive diagnosis was $5.65 \pm 1.06$ days. Tuberculosis was the most common among the infections, systemic onset juvenile idiopathic arthritis and Common acute lymphoblastic leukemia antigen positive B cell acute lymphoblastic leukemia were common causes of connective tissue disorder and malignancy, respectively.

The diagnosis was established by Phase II (33.3\%) and Phase III (34.8\%) investigations. Non-invasive and invasive investigations were useful in $56.3 \%$, and $43.7 \%$, respectively.

Conclusions: Infections are the most common cause of FUO in children followed by malignancy. A stepwise approach is useful in diagnosis. Infections and connective tissue disorders are diagnosed by non-invasive investigations while malignancy and miscellaneous conditions by invasive investigations. Focused clinical and diagnostic approach is mandated. J Microbiol Infect Dis 2019; 9(3):137-143.

Keywords: Acute lymphoblastic leukemia, algorithm, children, fever of unknown origin, children

\section{INTRODUCTION}

Fever of Unknown Origin (FUO) is one of the common clinical situations but the most challenging for the physician and often exhausting due to the requirement of elaborate diagnostic workup involving numerous procedures, which can sometimes fail to reveal the etiology $[1,2]$.

The incidence of FUO ranges from $0.5 \%$ to $3 \%$ $[3,4]$. There are well over two-hundred different reported causes of FUO [5]. To date, there are no well-designed published guidelines or evidence based recommendations and no gold standard diagnostic workup of FUO [6]. The general direction of evaluation varies based on patient presentation, geographic location, associated symptoms, environmental exposures, physician experience, and available testing techniques.

Changing clinical scenario in terms of varied clinical presentation and control of common infections and communicable diseases brought some uncommon etiology into focus. Identifying the etiology is not only useful in the management but also in the prevention of disease complications. Our study aimed to develop an insight into the causes of FUO in children and evaluated the clinical procedures useful in establishing the diagnosis.

\section{METHODS}

This was a prospective observational study conducted at a tertiary care hospital between 
May 2012 and April 2016 after obtaining approval from the Institutional Ethics Committee. This study was approved by the Institutional Ethics Committee, Rainbow Children's Hospital, Hyderabad, India. Children aged 1month-16 years admitted with FUO were included in the study; children with previously known immunosuppressive disease and suspected nosocomial infection were excluded [7].

After obtaining a written informed consent a detailed medical history and physical examination was done. Investigations were conducted according to an algorithm (Figure 1) and need basis. We followed a three stage FUO protocol in the patient assessment [8]. After evaluation, children were categorized according to the etiology of fever into that due to infection, connective tissue disorders, malignancy, miscellaneous conditions and undiagnosed fever.

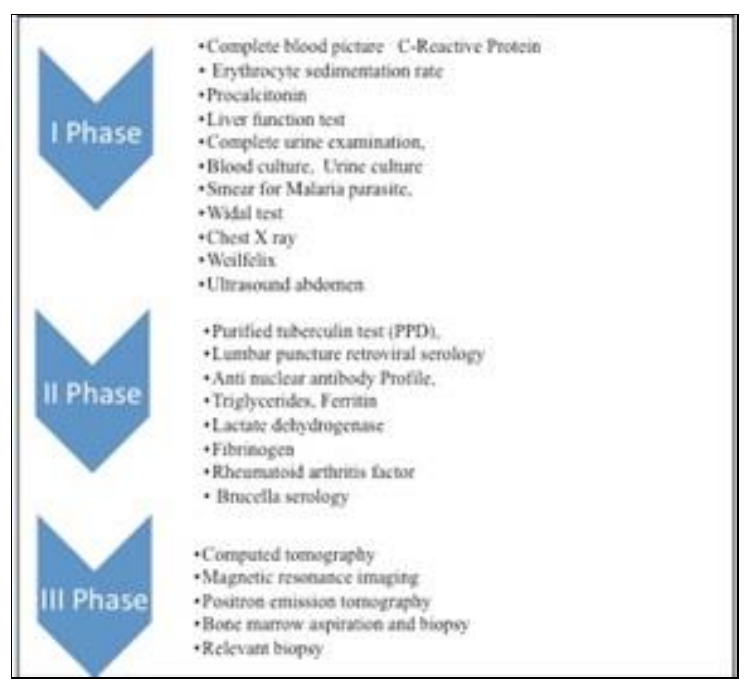

Figure 1. Step-wise investigations.

\section{Statistical Analysis}

The descriptive statistics was used; results were expressed as mean, standard deviation for continuous variables, and median, interquartile range (IQR), and percentage (\%) distribution for categorical variables. Tables and figures were used as appropriate. Statistical analysis was performed using SPSS, $20^{\text {th }}$ version).

\section{RESULTS}

Sixty-nine children meeting the study criteria were included. There were $40(58 \%)$ males and $29(42 \%)$ females. The mean \pm SD age of presentation was $82 \pm 52.4$ months $(6.8$ years \pm
4.4 ), range of $1-16$ years and median of 6.25 years.

Of 69 children, $33(48 \%)$ presented only with fever and $36(52 \%)$ with fever along with symptoms; joint pains $(n=10,27.7 \%)$, cough $(n=6,16.6 \%)$, maculopapular rash $(n=3,8.3 \%)$, weight loss $(n=7,19.4 \%)$. Other non-specific symptoms (headache, vomiting, and pain abdomen) were seen in ten (27.7\%) children.

The diagnosis of FUO was established in fifty-six $(81.2 \%)$ children. Infections ( $n=22, \quad 31.8 \%)$ malignancy $(14,20.2 \%)$ were the common causes (Figure 2). Bacterial infections were diagnosed in 16 cases $(72.7 \%)$, viral in 3 $(13.6 \%)$ and protozoal in $03(13.6 \%)$ as etiological factors. Table 1 shows various causes of FUO among different age groups. Those who remained undiagnosed either had a spontaneous recovery or went against medical advice. All children included in the study received prior antimicrobials and $80 \%$ of children referred from other hospitals.

Median duration of fever before admission was 28 days and interquartile range of 20-60 days, highest in malignancies (60 days) and least in infections (26 days). Mean duration between admission and definitive diagnosis was 5.65 days \pm 1.06 days. Etiology was established within a week of admission, connective tissue disorders and malignancy was identified faster (5 days) (Figure 2 ).

Tuberculosis $(8 / 22,36.4 \%$, pulmonary four 4 , extrapulmonary 4), brucellosis (three cases, $13.6 \%$ ) and rickettsia (3 cases, $13.6 \%$ ) were the common infections. Mean duration of fever in infections is 25.8 days. Median duration of fever among tuberculous patients was 21 days, with IQR 20-22 days. Common acute lymphoblastic leukemia antigen (CALLA) positive $B$ cell acute lymphoblastic leukemia (ALL) was most common malignancy diagnosed $(n=8)$. Among connective tissue disorders, systemic onset juvenile idiopathic arthritis (8), and systemic lupus erythematosus (2) were common. Mean duration of fever in malignancies was 59.8 days, 36.5 days for connective tissue disorders, 46.5 days for miscellaneous causes, and 39 days among those who remained undiagnosed.

Non-invasive and invasive investigations aided in establishing the diagnosis in $31(56.3 \%)$ and $25(43.7 \%)$ children, respectively (Figure 3 ). 
Complete blood picture (CBP) was abnormal in $73.9 \%$ with $50.7 \%$ children with Hemoglobin< $10 \mathrm{gm} / \mathrm{dl}$. High C-reactive protein $(\mathrm{CRP})>10$ was found in $72.4 \%$, and high erythrocyte sedimentation rate (ESR) more than 10 in $91 \%$. Serum lactate dehydrogenase (LDH) was abnormal in $81.5 \%$.

Table 2 and 3 show the causes of FUO identified at different level of investigation among the study population.

\section{Treatment and follow up}

Patients received treatment according to the diagnosis and as per the hospital treatment protocol. Antibiotics for the bacterial infections and anti-tubercular drugs for tuberculosis, chemotherapy for those with malignancy, nonsteroidal anti-inflammatory drugs for those with connective tissue disease. Steroids were given as appropriate. None had fever at the time of discharge.

\section{DISCUSSION}

Availability of new diagnostic techniques has expanded the horizon of diseases resulting in narrowing/widening of spectrum of etiology of FUO. Infectious diseases still are focus areas in the etiology of fever in developing countries though non-communicable causes such as malignancy, connective tissue disease are also on the rising trend. However, despite the recent advances in diagnostic techniques FUO remains a formidable challenge. Factors such as geography, age of the patients, socioeconomic factors, availability and accessibility to health care facility have a significant role in FUO [6]. Hence, establishing etiology is crucial in the management of the child with FUO.

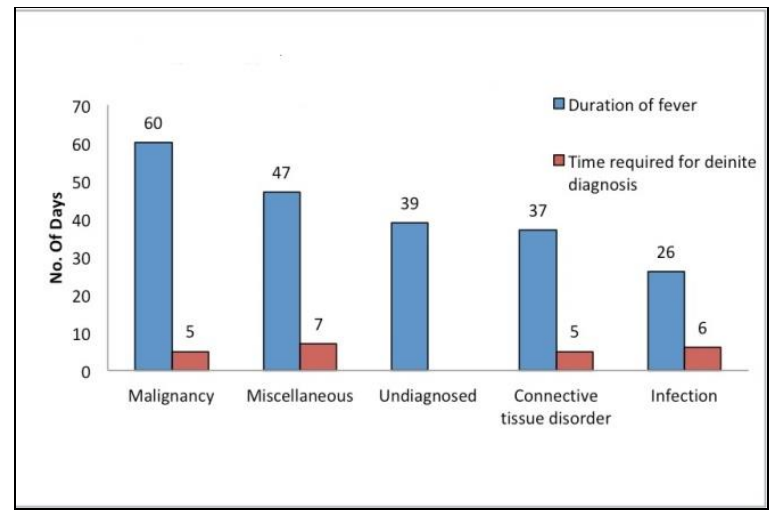

Figure 2. Comparison of duration of fever before hospitalization and time taken for diagnosis after hospitalization.

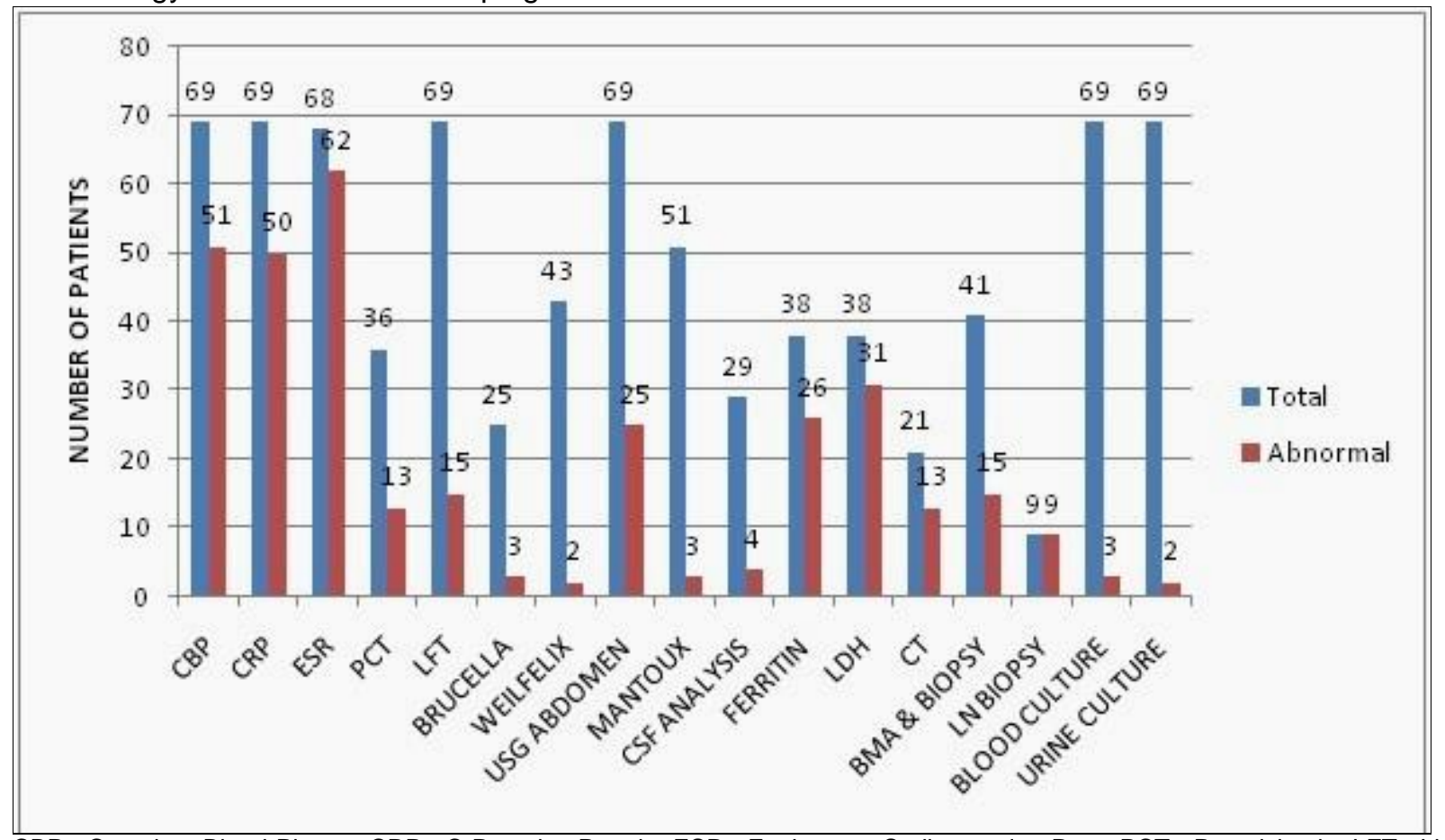

$\mathrm{CBP}=$ Complete Blood Picture; $\mathrm{CRP}=\mathrm{C}$-Reactive Protein; ESR= Erythrocyte Sedimentation Rate; PCT= Procalcitonin; LFT= Liver function tests; $\mathrm{LDH}=$ Lactate dehydrogenase; CSF analysis= Cerebrospinal fluid analysis; $C T=$ Computed Tomography; $L N$ biopsy = Lymph node biopsy.

Figure 3. .Investigations aided in establishing diagnosis. 
Table 1. Etiology of FUO among different age groups

\begin{tabular}{lccccc}
\hline Cause & $<1$ year & $2-5$ years & $>5-10$ years & $10-16$ years & Total \\
\hline Infectious disease & 1 & 7 & 9 & 5 & 22 \\
Malignancy & 0 & 3 & 9 & 2 & 14 \\
Collagen vascular disease & 0 & 5 & 2 & 3 & 10 \\
Miscellaneous & 0 & 4 & 1 & 4 & 10 \\
Undiagnosed & 1 & 6 & 5 & 13 \\
Total & $2(2.9 \%)$ & $25(36.2 \%)$ & $23(33.3 \%)$ & $19(27.5 \%)$ & 69 \\
\hline
\end{tabular}

Table 2. Etiologies of FUO identified by stepwise investigation process.

\begin{tabular}{|c|c|c|c|}
\hline Phase & Investigations & Diagnosis & n (\%) \\
\hline I & $\begin{array}{c}\text { CBP, CRP, ESR, Blood culture, Urine } \\
\text { culture, Widal test, Chest X-ray, Weil } \\
\text { Felix }\end{array}$ & Infections & $9(13.0 \%)$ \\
\hline II & $\begin{array}{c}\text { Purified tuberculin test, Retroviral } \\
\text { serology, ANA profile, LDH, Ferritin, } \\
\text { Brucella antibody }\end{array}$ & $\begin{array}{l}\text { Infections, Connective Tissue Diseases, } \\
\text { Miscellaneous conditions }\end{array}$ & $23(33.3 \%)$ \\
\hline III & $\begin{array}{c}\text { Bone-marrow aspiration \& biopsy, CT, } \\
\text { Lymph node biopsy, Colonoscopy }\end{array}$ & $\begin{array}{c}\text { Infections, Malignancy, Miscellaneous } \\
\text { conditions }\end{array}$ & 24 (34.8\%) \\
\hline
\end{tabular}

Table 3. Aetiology of FUO among study population.

\begin{tabular}{|c|c|c|}
\hline Etiology & $\mathrm{n}$ & Phase of Investigation \\
\hline \multicolumn{3}{|l|}{ Infections } \\
\hline Tuberculosis & 8 & II, III \\
\hline Brucella & 3 & $\mathrm{I}, \mathrm{II}$ \\
\hline Rickettsia & 3 & 1 \\
\hline Urinary tract infection & 2 & 1 \\
\hline Dengue fever with secondary HLH & 2 & I,III \\
\hline Salmonella infection & 1 & 1 \\
\hline Retroviral infection & 1 & II \\
\hline Liver abscess & 1 & I \\
\hline Pneumonia with secondary HLH & 1 & I,III \\
\hline \multicolumn{3}{|l|}{ Connective tissue disorders } \\
\hline SOJRA & 8 & II \\
\hline SLE & 2 & II \\
\hline \multicolumn{3}{|l|}{ Malignancy } \\
\hline CALLA positive B cell ALL & 8 & III \\
\hline Hodgkins lymphoma & 2 & III \\
\hline Non Hodgkins lymphoma & 2 & III \\
\hline T cell ALL & 1 & III \\
\hline AML & 1 & III \\
\hline \multicolumn{3}{|l|}{ Miscellaneous } \\
\hline Inflammatory bowel disease & 3 & III \\
\hline Primary immunodeficiency & 2 & III \\
\hline Inflammatory myositis & 1 & II \\
\hline Auto inflammatory syndrome & 1 & II \\
\hline $\mathrm{HLH}$ & 1 & II, III \\
\hline Kikuchi disease & 2 & III \\
\hline Undiagnosed & $13(18.8 \%)$ & \\
\hline Total & 69 & \\
\hline
\end{tabular}


Our study population had male preponderance $(58.0 \%)$, a similar observation reported by Chien et al [1]; mean age at presentation was 6.8 years, which is higher compared to the study by Hassan $\mathrm{RH}$ et al (5 year 4 months, 5 months-14 years) [9] but lower compared to the study by Chien YL et al [1]. Mean duration of fever before admission was $39 \pm 33$ days in our study, higher than that reported by Hassan $\mathrm{RH}$ et al (32 days, 18-5 years) [9]. Time taken to arrive at a definite diagnosis was $<1$ week in our study, a longer time for the same was reported by Hassan $\mathrm{RH}$ et al [9].

The general pattern of FUO in our study is comparable to previous studies of children in developing countries $(2,10-11)$, diagnosis was established in $56(81.2 \%)$ children. Chien $\mathrm{YL}$ et al established the diagnosis in $84.9 \%$ of study population [1] in contrast to $63.2 \%$ in 1978 [12] Sandoval $\mathrm{C}$ et al established diagnosis in $67.9 \%$ in 2014 [13].

We report infections (31.8\%) and malignancies $(20.2 \%)$ as the most common followed by connective tissue disorder, miscellaneous and undiagnosed causes. This pattern is similar to the previous reports $[1,14,15]$. Infections retained their first place in the list as reported by Cruz Guerrero G et al [12] since 1978 (64.5\%), though there is a reduction. Sandoval $C$ et al [13] report a similar order of infections $(88.4 \%)$, malignancy $(4.8 \%)$, rheumatologic $(4.8 \%)$ and Kawasaki disease (2.8\%). Enteric fever and urinary tract infections were common among infections. In our study, bacterial infections $(72.7 \%)$ were common compared to viral $(13.6 \%)$ tuberculosis is the most common cause $(36.36 \%)$ similar to the previous reports $[11,12]$. Three patients each had brucellosis and rickettsial disease. Our observations support inclusion of brucellosis in differential diagnosis [16], and ricketsial disease as reported by Chien $Y L$ et al [1] Children with infectious diseases received a course of antibiotics prior to hospitalization.

Malignancies were the second most common cause of FUO in our study; CALLA positive B cell ALL (57.14\%), Hodgkin's lymphoma (14.23\%), Non-Hodgkin's lymphoma (14.2\%) were frequent. Previous reports placed malignancies in the $3 r d$ place as a cause of
FUO, of late has jumped to 2nd place replacing collagen vascular disorders [1]. ALL was the most common among malignancies in children presenting as FUO [1] and our study is in support of this.

Undiagnosed causes are the most challenging cases worldwide. Kim et al [17] faced this challenge in $43 \%$ of their patients and accounted for $18.84 \%$ in our study. A recent study from our country reported that only $12.0 \%$ cases remained undiagnosed. This could be due to smaller number of patients with shorter duration of fever [18]. Chien YL et al [1] report 15.05\% patients remained undiagnosed. Pediatricians have to focus on this area for betterment. Clinical judgment and optimal use of available modern diagnostic facilities is highly recommended. It is necessary that the pediatrician should be adequately trained to identify the cause of the fever.

Crump JA et al [19] reported bacterial and fungal blood borne infections (3.4\%) and bacterial zoonosis $(20.2 \%)$. Salmonella typhi $(25.9 \%)$ and Streptococcus pneumoniae (22.2\%) were bacterial blood borne infections; brucellosis $(2.0 \%)$, leptospirosis $(7.7 \%)$, spotted fever group rickettsioses $(7.4 \%)$ and $Q$ fever $(2.6 \%)$ were reported bacterial zoonotic infections. Malaria was clinically diagnosed in $60.4 \%$ but was established only in $1.3 \%$.

Physical examination is an essential tool in the diagnosis and is mandated. Skin rashes, visible nodules in the neck, mass in the abdomen often lead to the diagnosis. Diagnosis is based on 3 stage protocol as universally practiced. We established diagnosis in $<7$ days in $100 \%$ patients; infectious diseases were diagnosed by stage I \& II, malignancies at stage III and miscellaneous by stage II \& III investigations. Non-invasive investigations proved valid in $56.3 \%$ while non-invasive in $43.7 \%$ children. Tuberculosis and malignancy required a battery of investigations to confirm the diagnosis, while the miscellaneous causes required exhaustive laboratory investigations.

All our patients had complete resolution except for those who were discharged against medical advice and lost to follow up $(n=4.5 .7 \%)$. 
Sandoval C report complete resolution in $98 \%$ [13]. There was no mortality in our study.

\section{Utility of investigations in diagnostic process}

Inspite of high range of abnormality in CRP, ESR, LDH, serum ferritin none of these directly led to a diagnosis but together aided in diagnosis of infections and connective tissue diseases supporting the observation of Xie $\mathrm{T}$ et al. [20]. Apart from the standard investigations for tuberculosis, Brucella serology, blood culture, urine culture found to be effective in infectious diseases. Our study indicated the diagnostic role of Bone marrow aspiration and biopsy $(n=41)$ that led to final diagnosis in all; it was useful in diagnosing malignancies, hemophagocytic lymphohistiocytosis (HLH), infections, supporting the views of Labrador $\mathrm{J}$ et al. [21]. We found Lymph node biopsy as another useful diagnostic tool. Of the imaging techniques CT (chest/abdomen) was the most useful investigation. Chest $X$ ray and USG abdomen were inconclusive and did not contribute to a final diagnosis, similar to the report by Steele RW et al. [22].

First line of investigations were useful in only in infections, but gave a clue for further workup in other etiologies of FUO. Malignancies and miscellaneous conditions required third line of investigations.

\section{Conclusion}

FUO remains one of the challenging clinical entities among pediatric patients despite the availability of advanced investigational tools. Establishing etiology in these cases still poses a challenge. Infections with tuberculosis the most common are still in the top of the list of etiologies of FUO. Non-invasive investigations are helpful for the diagnosis of Infections and connective tissue disorders while Invasive investigations are required to establish the diagnosis of malignancy and miscellaneous conditions. Clinical judgment supported by step up investigations is essential in establishing the diagnosis. Undiagnosed cases ended up in spontaneous resolution or incomplete workup as they went against medical advice.

\section{ACKNOWLEDGMENTS}

Authors acknowledge the support of all staff, Department of Pediatrics, Rainbow Children's
Hospital, Hyderabad, India. Authors thank Dr Vivekananda Murthy, consultant Biostatistician, Rainbow Children's Hospital, Hyderabad for the statistical analysis and Dr. M. S. Latha Consultant, Pediatric Research \& Medical Education, Rainbow Children's Hospital, Hyderabad, India, for writing assistance.

Declaration of Conflicting Interests: The authors declare that they have no conflict of interest.

Funding: None declared.

\section{REFERENCES}

1. Chien YL, Huang FL, Huang CM, Chen PY. Clinical approach to fever of unknown origin in children. J Microbiol Immunol Infect 2017; 50(6):893-898.

2. Mouaket AE, el-Ghanim MM, Abd-el-Al YK, alQuod N. Prolonged unexplained pyrexia: a review of 221 paediatric cases from Kuwait. Infection 1990; 18(4):226-229.

3. Cho CY, Lai CC, Lee ML, et al. Clinical analysis of fever of unknown origin in children: A 10-year experience in a northern Taiwan medical center. $J$ Microbiol. Immunol Infect 2017; 50(1):40-45.

4. Chouchane $\mathrm{S}$, Chouchane $\mathrm{CH}$, Ben Meriem $\mathrm{CH}$, et al. Prolonged fever in children.Retrospective study of 67 cases. Archives de Pediatrie 2004; 11(11):1319-1325.

5. Cunha BA, Lortholary O, Cunha CB. Fever of unknown origin: a clinical approach. Am J Med 2015; 128(10):1138.e1-1138.e15.

6. Nield LS, Kamat D. Fever. In: Kliegman RM, Stanton BF, St Geme JW, Schor NF, Behrman RF, editors. Nelson Textbook of Pediatrics. $19^{\text {th }}$ ed. Philadelphia, PA: Saunders Elsevier; 2011, pp. e169-1-e169-3.

7. Durrack DT, Streat AC. Fever of unknown origin reexamined and redefined. Curr Clin Top infect Dis 1991; 11:35-51.

8. Tezer H, Ceyhan M, Kara A, Cengiz AB, Devrim I, Seçmeer $G$. Fever of unknown origin in children: the experience of one center in Turkey. Turk $J$ Pediatr 2012; 54(6):583-589.

9. Hassan $\mathrm{RH}$, Fouda AE, Kandil SM. Fever of Unknown Origin in Children: A 6 year- Experience in a Tertiary Pediatric Egyptian Hospital. Int $\mathrm{J}$ Health Sci (Qassim) 2014; 8(1):13-19.

10. Cogulu O, Koturoglu G, Kurugol Z, Ozkinay F, Vardar F, Ozkinay C. Evaluation of 80 children with prolonged fever. Pediatr Int. 2003; 45(5):564569.

11. Harrison's Fever of unknown origin. In: Longo $D$, Fauci A, Kasper D (Eds). Principles of Internal 
Medicine, $18^{\text {th }}$ edition. McGraw Hill; 2012, pp:158164.

12. Cruz Guerrero G, Navarro González J, Cintado Bueno C. [Fever of unknown origin in children]. An Esp Pediatr 1978; 11(10):683-692. [article in Spanish].

13. Sandoval C, Pinochet C, Peña A, Rabello $M$, Prado A, Viviani T. Fever of unknown origin: a challenge for the pediatric infectious diseases specialist. Rev Chilena Infectol 2014; 31(1):87-91 [Abstract only, article in Spanish].

14. Kejariwal D, Sarkar N, Chakraborti SK, Agarwal V, Roy S. Pyrexia of unknown origin: a prospective study of 100 cases. J Postgrad Med 2001; 47(2):104-107.

15. Joshi N, Rajeshwari K, Dubey AP, Singh T, Kaur R. Clinical spectrum of fever of unknown origin among Indian children. Ann Trop Paediatr 2008; 28(4):261-266.

16. Ciftdoğan DY, Bayram N, Vardar F. Brucellosis as a cause of fever of unknown origin in children admitted to a tertiary hospital in the Aegean region of Turkey. Vector Borne Zoonotic Dis 2011; 11(8):1037-1040.

17. Kim YS, Kim KR, Kang JM, Kim JM, Kim YJ. Etiology and clinical characteristics of fever of unknown origin in children: a 15-year experience in a single center. Korean J Pediatr 2017; 60(3):77-85.

18. Landge AA, Singhal T. Etiology of Fever of Unknown Origin in Children from Mumbai, India. Indian Pediatr 2018; 55(1):71-72.

19. Crump JA, Morrissey AB, Nicholson WL, et al. Etiology of Severe Non-malaria Febrile Illness in Northern Tanzania: A Prospective Cohort Study. Picardeau M, ed. PLoS Negl Trop Dis 2013; 7(7):e2324.

20. Xie T, Pan J-H, Zhang X. [Value of combined measurement of C-reactive protein, erythrocyte sedimentation rate, lactate dehydrogenase and serum ferritin in etiological diagnosis of fever of unknown origin in children]. Zhongguo Dang Dai Er Ke Za Zhi 2015; 17(9):950-955.

21. Labrador J, Pérez-López E, Martín A, Cabrero M, Puig N, Díez-Campelo M. Diagnostic utility of bone marrow examination for the assessment of patients with fever of unknown origin: a 10-year single-centre experience. Intern Med J 2014; 44(6):610-612.

22. Steele RW, Jones SM, Lowe BA, Glasier CM. Usefulness of scanning procedures for diagnosis of fever of unknown origin in children. $J$ Pediatr $1991 ; 119(4): 526-530$. 